(e.g. 65 versus 43 claims per 1,000 workers for women and men respectively in labourer occupations in processing/manufacturing), and for concussions (e.g. increase from 13 to 25 claims versus from 12 to 16 claims per 1,000 workers for women and men respectively in transportation/equipment operation occupations over the study period). We observed higher ratios of disallowed to accepted claims for women compared to men for ASTDs (1.4 versus 0.5) and hearing loss (4.1 versus 0.4). We observed longer durations to final accepted claim eligibility decisions for women compared to men for ASTDs (e.g. 49 versus 43 days at the 50th percentile) and hearing loss (238 versus 204 days), but not concussions (7 days each).

Conclusion The findings warrant further investigation to understand the increased risks of ASTDs and concussions among women compared to men, especially in occupations that have been traditionally male-dominated; and for potential gender/sex biases in the adjudication and recognition of workrelated cumulative injuries and disorders among women.

\section{S-95 CHANGES IN RESPIRATORY SYMPTOMS, SPIROMETRY, AND EXHALED NITRIC OXIDE AMONG HOME CARE AIDES PERFORMING CLEANING AND DISINFECTING USING DIFFERENT PRODUCTS: A LONGITUDINAL REPEATED MEASURES STUDY}

${ }^{1}$ Margaret Quinn, Susan Sama, Noor Sheikh, David Kriebel, Rebecca Gore, John Lindberg, Catherine Galligan, Pia Markkanen, Nicole Karlsson, Abbas Virji, Ryan LeBouf. 'University of Massachusetts Lowell, United States

\subsection{6/OEM-2021-EPI.407}

Objectives Occupational and population-based studies show that cleaning and disinfecting (C\&D) tasks can increase the risk of adverse respiratory symptoms. However, quantitative evaluation of specific C\&D products and practices and their impacts on respiratory health are limited. Previously, we found that $80 \%$ of home care (HC) aide visits to clients' homes involve C\&D. Increasingly, C\&D ingredients are combined in single products that often contain bleach, quaternary ammonium compounds (QACs) or other respiratory irritants. Socalled 'green' C\&D products might be better alternatives but have not been evaluated for respiratory health. This study evaluated the relationship between the use of conventional and 'green' C\&D products on respiratory outcomes.

Methods A longitudinal repeated measures study design was used. Twenty HC aides each participated in four sessions in an environmental assessment laboratory where a simulated bathroom with fixtures (toilet, tub/shower, sink) was built according to residential construction specifications. During each 40-minute session, aides performed typical C\&D tasks. Three multi-purpose spray C\&D products - one bleach-based (1-5\% by weight sodium hypochlorite), one QACs-based (including benzyldimethyldodecylammonium chloride, benzyldimethyltetradecylammonium chloride, and benzyldimethylhexadecylammonium chloride) and one 'green' (plant-based thymol, active disinfecting ingredient) - and distilled water in a spray bottle were randomized among the aides' sessions. Respiratory symptoms, spirometry, and exhaled nitric oxide (eNO, a biomarker of airway response) were measured pre-and postsession.
Results Aides reported more respiratory symptoms following use of the bleach-based product (eye, nose, throat irritation, cough, and difficulty breathing) and experienced a reduction in FEV1 $(-4.3 \%, 95 \% \mathrm{CI}:-7.4$ to -1.1$)$, compared to the other products and to distilled water. Mean eNO decreased by 10 ppb (95\% CI: -8 to $-13 \mathrm{ppb}$ ) following bleach-based product use compared to the other products and to distilled water.

Conclusions Bleach-based C\&D products may cause acute adverse respiratory changes after a relatively short exposure representative of C\&D in $\mathrm{HC}$.

\section{S-106 RISK OF EXPOSURE TO A SARS-COV-2 INFECTION AT WORK: DEVELOPMENT OF A JOB EXPOSURE MATRIX (COVID-19-JEM) FOR DENMARK, THE NETHERLANDS AND THE UNITED KINGDOM}

${ }^{1}$ Karen Oude Hengel, Lex Burdorf, Anjoeka Pronk, Vivi Schlünssen, Zara Ann Stokholm, Henrik Albert Kolstad, Karin van Veldhoven, Ioannis Basinas, Martie van Tongeren, Susan Peters. ${ }^{1} T N O$, Netherlands

\subsection{6/OEM-2021-EPI.408}

Introduction As workplaces may be one of the key settings in the spread of SARS-COV-2 infections, among both essential and non-essential workers, it is important to assess the occupations at increased risk of exposure to SARS-COV-2 in large study populations.

Objectives This study aimed to construct a job-exposure matrix (JEM) for the risk of becoming infected with SARSCOV-2 in an occupational setting.

Methods Experts in occupational epidemiology from three European countries (Denmark, the Netherlands and United Kingdom) defined relevant exposure and workplace characteristics with regard to possible exposure to SARS-COV-2. Within an iterative qualitative process, experts rated the different dimensions of the COVID-19-JEM for each job title within the International Standard Classification of Occupations 2008 (ISCO-08). The agreement scores including confidence intervals, weighted kappas, and explained variances were estimated.

Results The COVID-19-JEM contains four determinants of transmission risk (number of people, type of contacts, indirect contact and location), two mitigation measures (social distancing and face covering), and two social factors (income insecurity and migrant workers). Agreement scores ranged from 0.58 $(95 \% \mathrm{CI} 0.55 ; 0.61)$ for 'number of people' to $0.76(95 \% \mathrm{CI}$ $0.74 ; 0.78)$ for 'type of contacts'. Agreement scores ranged from 0.58 (95\%CI $0.55 ; 0.61)$ for 'number of people' to 0.76 (95\%CI $0.74 ; 0.78)$ for 'type of contacts. Weighted kappas ranged from 0.60 for 'face covering' to 0.80 for 'indirect contact'. Due to some between-country differences, COVID-19JEMs are separately presented for Denmark, the Netherlands and the United Kingdom.

Conclusions The COVID-19-JEM provides risk estimates at population level of the eight dimensions related to a SARSCOV-2 infection at the workplace, and is a valuable tool for epidemiological studies. Additionally, the eight dimensions of the COVID-19-JEM could also be used for other communicable diseases at worksites. 